\title{
Gender Dysphoria and Body Integrity Identity Disorder: Similarities and Differences
}

\author{
Alicia Garcia-Falgueras \\ The Official College of Psychologists, Madrid, Spain \\ Email: algarfal@gmail.com
}

Received November $21^{\text {st }}, 2013$; revised December $22^{\text {nd }}, 2013$; accepted January $17^{\text {th }}, 2014$

\begin{abstract}
Copyright (c) 2014 Alicia Garcia-Falgueras. This is an open access article distributed under the Creative Commons Attribution License, which permits unrestricted use, distribution, and reproduction in any medium, provided the original work is properly cited. In accordance of the Creative Commons Attribution License all Copyrights (C) 2014 are reserved for SCIRP and the owner of the intellectual property Alicia Garcia-Falgueras. All Copyright (C) 2014 are guarded by law and by SCIRP as a guardian.
\end{abstract}

Gender Dysphoria and Body Integrity Identity Disorder are sometimes together in the $19 \%$ of the cases. Other discomfort diseases related to identity, body scheme and/or integrity are discussed in relation to Gender Dysphoria. Because persons experiencing Gender Dysphoria need a precise diagnostic that protects their access to care and will not be used against them in social, occupational or legal areas a distinction diseases is provided in this text, because a meticulous description with clear exclusion criteria is required.

Keywords: Gender Dysphoria; Delusional Disorder-Somatic; Body Dysmorphic Disorder; Body Integrity Identity Disorder; Parietal Cortex

\section{Introduction: Concepts, Definitions and Considerations for Identity}

Identity and self are concepts not easy to describe or quantify. There has been thousands of thinkers and Philosophers across History and time who pursued to add some clarity to those evasive ideas, because at the time one thinks about them, they change their size and entity.

In 1690, J. Locke realized memory had an important role for personal identity, as including our experiences and learning processes as part of our way to be, that is different from the rest. Locke hold personal identity as a matter of psychological continuity (Nimbalka, 2011).

For declarative and procedural memories consolidation is required the hippocampus were bilaterally activated while the memory is being created, and later that event is consolidated and strengthened in the cortex, together with amygdale and orbitofrontal participation (Eichenbaum et al., 1996; Fink et al., 1996; Viard et al., 2007). Although there are several brain networks to create a memory. Autobiographical memory is the one related to build our own identity, but there are quite an agreement between different authors, concerning to the necessity of awareness for timing course and an existence of a specifically personal engaged to the event to remember related to its meaning and to a motivation for being involved in the reconstruction of one's own past and autobiographical memory (Fink et al., 1996; Fink, 2003). Amygdale (emotions) and will (anterior cingulated cortex) might be important brain areas to be involved in fixing memories, including autobiographical (Swaab, personal comm.).

This role was such a crucial aspect of identity for Locke to say if someone does not remember nothing of his or her past, then he or she "literally has no identity" (Locke, 1975). This consideration of identity as the same as memory was defined by Joseph Butler as a "wonderful mistake": "In other words, I can remember only my own experiences, but it is not my memory of an experience that makes it mine; rather, I remember it only because it's already mine. So while memory can reveal my identity with some past experiencer, it does not make that experiencer me. What I am remembering", then, insists Butler, "are the experiences of a substance, namely, the same substance that constitutes me now" (Butler, 1975).

Later on, the philosopher and psychologist William James at the end of $19^{\text {th }}$ century tried to reorganize ideas for identity (Sollberger, 2013). He made a core distinction between two aspects of identity: the "me" and the "I". The former referring to the permanence and continuity in present time and space of the self while the later also were including the past experiences as an integral part of consciousness. Kant were also more in line with James, since he sustained all knowledge, including self-knowledge, must be derived a posteriori from experiences of sensation and reflection. Although, perhaps the concepts of $I$, me, and mine are built empirically, but perhaps the primitive sense of the self or identity, as distinct from other objects and people in the environment, is given a priori. Self-consciousness for Kant therefore implies a priori knowledge about the necessary and universal truth expressed in this principle of apperception, (the lens of past experiences; (Ott, 2004)) through which identity is built a posteriori, but the original primitive $a$ priori knowledge cannot be based on experience.

Nowadays it is accepted memory is not only for identity as Locke sustained, but only the episodic memory as our autobiographical memory about the self for the events and experiences in our lives, which includes a mental representation of the self as the main acting role for some action, while other memories, 
such as semantic memory, are the personal generic knowledge about the world (Kihlstrom \& Klein, 1997).

\section{Gender Dysphoria (GD)}

Being a woman or a man is a very relevant aspect of ourselves, configuring our behavior and preferences and also the social expectations. Transsexualism, the most extreme form of Gender Dysphoria, is an individual's unshakable conviction of belonging to the opposite sex than the chromosomes say, which often leads to a request for sex-reassignment surgery and hormonal treatment for life (Blanchard, 1993; Cohen-Kettenis \& Gooren, 1999). Transsexual people desire to live and be accepted as a member of the gender opposite to that assigned at birth (Hembree et al., 2009). The term Male-to-Female (MtF) transsexual refers to a chromosomally male who identified on the female gender; the term Female-to-Male (FtM) transsexual means a chromosomally female person who identified on the male gender. Gender dysphoria (GD) is a DSM-V diagnosis that recently has been separated from Sexual Dysfunctions and Paraphillic Disorders because persons experiencing gender dysphoria need a diagnostic term that protects their access to care and will not be used against them in social, occupational or legal areas. In DSM-IV-TR it is defined as:

A) A strong and persistent cross-gender identification, combined with a persistent discomfort with one's sex or sense of inappropriateness in the role of that sex, causes clinically significant distress.

B) Persistent discomfort with his or her sex or sense of inappropriateness in the role of that sex.

C) The disturbance is not concurrent with a physical intersex condition.

D) The disturbance causes clinically significant distress or impairment in social, occupational or other important areas of functioning.

Usually the gender assigned at birth is that one corresponding to the chromosomal information, but many exceptions happens considering only genetic data (Kandhelwal et al., 2010). The reason why this criteria is still very used is because these two parameters (chromosomes-gender) are practically always correlated in an animal (Ngun et al., 2011). Recently, Australian and after them German legislation, which went into effect on Friday November $1^{\text {st }}$ in 2013, were enacted in order to give parents and children more time before making life-changing sex reassignment decisions in cases of intersex genital characteristics at birth. This will happen in German legislation having a third option (blank for gender designation box in babies whose gender is not clear at birth) only of their birth certificates, not other legal registries such as passports, being possible to change this blank designation later on to male or female or can be left blank indefinitely (Stafford, 2013).

Only in $23 \%$ of cases (1/3 according to the DSM-V) does a childhood gender problem leading to transsexuality in adulthood. With regard to sexual orientation, the most likely outcome of childhood gender identity disorder is adult homosexuality or bisexuality. This population is served by clinicians (Gender Teams) because they usually suffer from abuses and on one-fourth of patients reported childhood maltreatment (Bandini et al., 2011).

According to the onset time, transsexuality can be divided in two different courses: early and late onset. In the early one, the discomfort is present since the beginning of cross gender iden- tification, between 2 and 4 years old. In late onset the cross gender identification appears during puberty or adulthood, in a more gradually way and being concurrent sometimes with Transvestism Fetishism (DSM-IV-TR). It must be noted, however, that gender identity development is intrinsically programmed and there is no way of prevention for the disorder (Looy \& Bouma, 2005). On the other hand, some specific differences in onset timing might be happening between sexes, for Male-to-Female and Female-to-Male transsexuals (Lawrence, 2010).

There are still many confusions and doubts about what transsexualism is in general population. The reason why might be related to some mixed definitions or not boundaries well established. For clarifying purposes, here we would like to explain what is NOT transsexualism (Table 1) (as the extreme Gender Dysforia form):

\section{A) It is not an extreme form of homosexuality.}

Although homosexuality is not included in the DSM any more, some confusion it is still surrounding the two concepts: gender dysphoria and gender orientation are two independent processes in our brain. Neuroanatomical studies have shown there are some brain regions located in the hypothalamus which were related to sexual orientation in its volume-such as the subdivision INAH3-(LeVay, 1991) and also to gender dysphoria in its volume and number of neurons (Garcia-Falgueras \& Swaab, 2008). Other regions were related only to gender dysphoria in its intermediate values for volume and number of cells -INAH1-(Garcia-Falgueras et al., 2011) and the other region in human hypothalamus were not different among man and woman, nor related to sexual orientation or to gender dysphoria —INAH4-(Allen et al., 1989; LeVay, 1991; Garcia-Falgueras \& Swaab, 2008; Garcia-Falgueras et al., 2011).

On the other hand, there are many reasons to logically consider sexual orientation and gender dysphoria as different processes in our brains. For instance, it is widely accepted, since Kinsey's scales, there are many grades in sexuality, defined as a continuum from 0 to 6 , from exclusive heterosexual behavior to exclusive homosexual behavior. While for gender dysphoria there are two categories (male to female and female to male) although a third one can be also considered in cases of gender indeterminacy at birth (Stafford, 2013). Hypothetically those characteristics measured by different grades in scales might be belonging to different specialization brain networks, although they could share some components, such are those related to sexual arousal or libido which are located in the brain in the insula, the inferior and middle frontal gyrus and the hypothalamus as well (Hu et al., 2008), also incuding more cortical areas such as the anterior cingulated cortex, the anterior temporal cortex, and the ventral globus pallidus (Rauch et al., 1999).

B) It is not a delusional disorder, somatic type.

This is a primary disorder that is diagnosed when prominent nonbizarre delusions coming from the own body (odors, malformations, insects, etc.) are present for at least one month and the symptoms criteria for Schizophrenia have never been met. Hallucinations may be present but auditory or visual hallucinations cannot be prominent. For the somatic type the delusions are mainly related to physical defect, functions or general medical condition (DSM-IV-TR). The exclusion criteria for Gender Dysphoria might be:

$\left.1^{\text {st }}\right)$ the prominent nonbizarre delusions are never related to the gender, role or sex, but with some physical defect or general 
Table 1.

Common aspects and main differences between Gender Dysphoria, homosexuality and some DSM disorders.

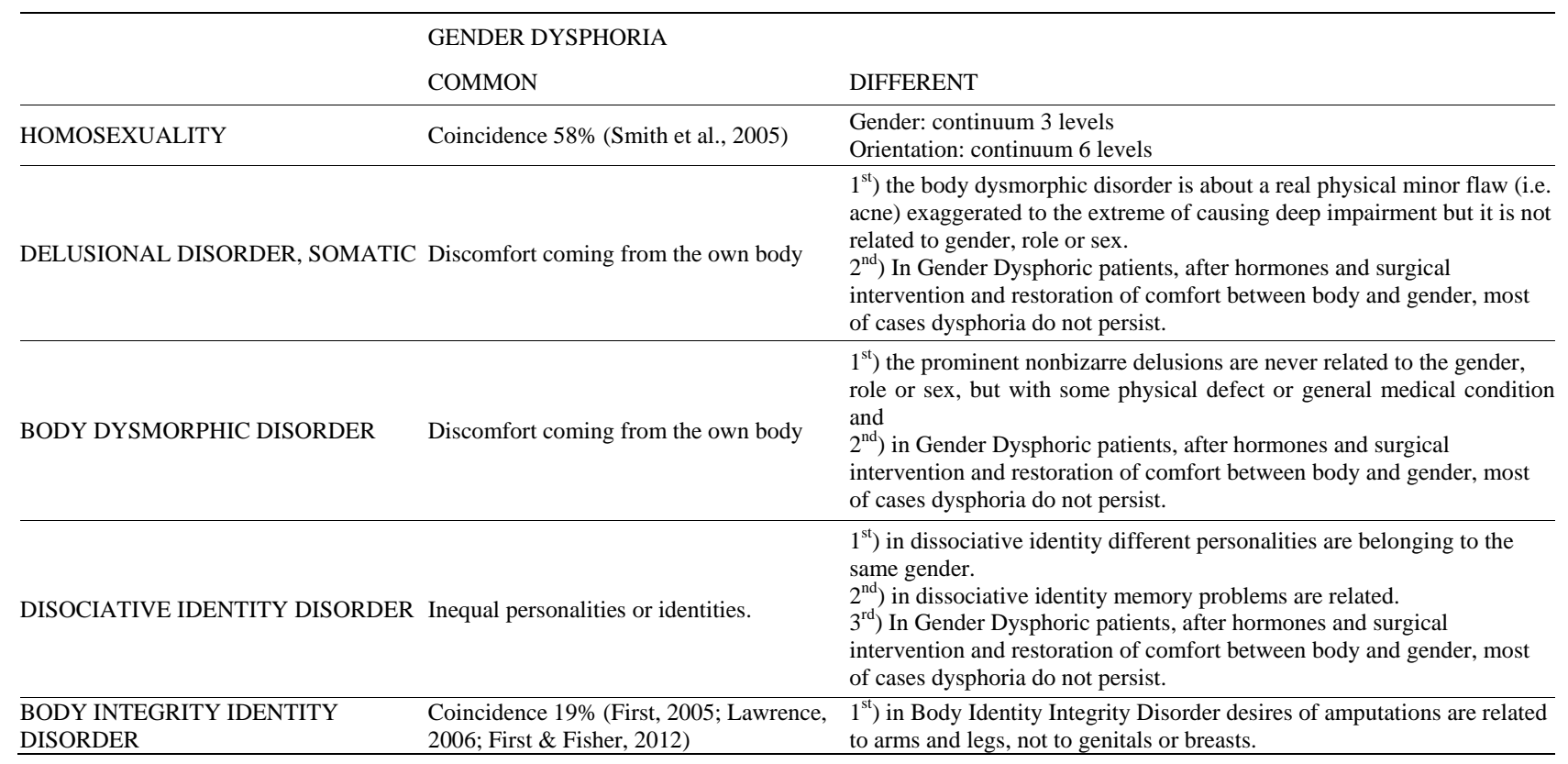

medical condition and

$2^{\text {nd }}$ ) In Gender Dysphoric patients, after hormones and surgical intervention and restoration of comfort between body and gender, most of cases dysphoria do not persist.

C) It is not a body dysmorphic disorder

Body dysmorphic disorder is a secondary somatoform disorder marked by a preoccupation and perpetual negative thoughts about their appearance with pain and discomfort. It is based on a imagined or trivial defect in appearance (usually related to skin, hair or nose) that causes clinically significant distress or impairment in social, occupational or other important areas of functioning. The exclusion criteria for Gender Dysphoria might be:

$1^{\text {st }}$ ) the body dysmorphic disorder is about a real physical minor flaw (i.e. acne) exaggerated to the extreme of causing deep impairment but it is not related to gender, role or sex.

$2^{\text {nd }}$ ) In Gender Dysphoric patients, after hormones and surgical intervention and restoration of comfort between body and gender, most of cases dysphoria do not persist.

D) It is not a dissociative identity disorder

DSM-IV-TR defines a dissociative disorder or multiple personality disorder as an extremely rare mental secondary disorder characterized by at least two distinct and relatively enduring identities or dissociative personality states that alternatively control a person's behavior, accompanied by memory impairments, lapsus and asymmetric amnesia. The exclusion criteria for Gender Dysphoria might be:

$1^{\text {st }}$ ) in dissociative identity different personalities are belonging to the same gender.

$2^{\text {nd }}$ ) in dissociative identity memory problems are related.

$3^{\text {rd }}$ ) In Gender Dysphoric patients, after hormones and surgical intervention and restoration of comfort between body and gender, most of cases dysphoria do not persist.

E) It is not a Body Identity Integrity Disorder (BIID)

Currently BIID is not included in the International Statistical Classification of Diseases $11^{\text {th }}$ revision nor in the Diagnostic and Statistical Manual of Mental Disorders IV or V. As such this disorder is often not known to surgeons, neurologist and psychiatrists.

Although both, the BIID and the transsexual desire of gonadectomy could be defined as a deep discomfort sensations that causes clinically significant distress to the patient, in both disorders patients recognize reality, meaning those discomfort sensations are illusions, not delusions. In both cases, after surgical restoration discomfort between body and gender or identity does not persist. Those people have in common that they are preoccupied (defined as extreme or excessive concern) with their body concept. That preoccupation causes clinically significant distress (depressed mood, anxiety, shame) or impairment in occupational or other important social areas. The distress increases and intensifies the desire of changing their bodies.

The unique exclusion criteria for Gender Dysphoria might be:

$1^{\text {st }}$ ) in Body Identity Integrity Disorder desires of amputations are related to arms and legs, not to genitals or breasts.

Then, could be those diseases related someway in the brain?

Firstly described as apotemnophile (amputation lovers) by Money et al. (1977) and most recently as Xenomelia (McGeogh et al., 2011; Brugger et al., 2013), a holdover from sexological research at Johns Hopkins in the 1970s, Body Integrity Identity Disorder (BIID) is used to describe people who feel from an early age that part of their body does not belong to them and they want to get rid of it, no matter what the cost is. They do not accept a particular limb as part of their body, even if it there's nothing wrong with its structure and function.

Neuroanatomically the BIID is characterized by an increased excitability of the dorsal-horn neurons, a reduction of inhibitory processes, and structural changes at the central nerve endings of the primary sensory neurons, the interneurons and the projection neurons. This central sensitization is mediated by the NMDA receptor and its transmitter is glutamate (Flor, 2002). Thalamic stimulation and recordings in human amputees have 
shown that reorganizational changes also occur at the thalamic level and are closely related to the perception of phantom limbs and phantom-limb pain. Tactile stimulation for undesired limbs causes a different brain activity (van Dijk et al., 2013). It has been suggested an absent memory process by a Hebbian learning mechanism for the limbs after amputation that could explain the weak phantom feelings (Ramachandram \& Hirstein, 1998). After the amputation, a cortical reorganization via longrange horizontal collateral pyramidal neurons through the GABA releasing might be occurring adjacent to the deafferented areas (DeFelipe et al., 1986).

BIID patients usually report thinking about their perceived appearance flaws for an average of 3 - 8 hours a day and about one quarter report for more than 8 hours a day (Phillips et al., 2010). In BIID different motivations for wanting an amputation have been described and they usually report more than one reason, although restoring identity is much more likely to be reported as primary (First, 2005). This pathology is usually strongly associated with high levels of social anxiety and some obsessive compulsive behaviors (i.e. mirror checking) have been described. Very poor functioning and high levels or rates of depression, anxiety, social anxiety, anger/hostility, suicidality and other proxy measures of distress are usually described (Phillips et al., 2010). There is a small subgroup of Gender Dysphoric patients who also present with symptoms relevant to BIID (Phillips et al., 2010) or BIID patients that present similar symptoms that Gender Dysphoric (First, 2005; Lawrence, 2006; First \& Fisher, 2012).

The conviction that a lower leg or arm does not belong to them develops at an early age, generally when patients are a child, or sometimes as a young adult. A child with BIID will cut figures out of newspapers, and then chop off the leg that they want to have amputated themselves. Although very little research has been done during development, several similarities were found for body dysmorphic disorders (BDD) between youth and adults (Phillips et al., 2010). Some patients have these feeling increased progressively over his early adult years and would intensify these feelings when they are under stress (First, 2005). This leads to an overpowering desire for amputation. Only once their limbs have been amputated, they do feel "complete". Surgeons who carry out these requests run the risk of being condemned for amputating a healthy limb. It seems that two-thirds of those patients, who do ultimately manage to have an amputation, damage their unwanted limb to the extent that it has to be amputated. Sometimes this involves putting their whole life in danger by putting a bullet through the kneecap, freezing the leg or using a saw to do the job themselves and paradoxically they finally "feel complete" and with the only regret of no having done it sooner. They can even get agitated, extremely envious or even sexually arousal activated when they see handicapped people who have to live without a leg or an arm, and sometimes this is the moment that they first realize that this is what they themselves want (First, 2005; First \& Fisher, 2012). Often they will try to imitate the desired situation as close as possible, for example by using an elastic bandage to bind a leg against their buttocks, wearing wide trousers which hide the lower part of the leg, folding up a trouser leg, walking with crutches or using a wheelchair. Males are more likely affected by BIID than females (Braam et al., 2006).

The connection with transsexuality is especially intriguing due to the percentage (19 percent) of BIID patients who also exhibit a gender identity problem and the high percentage of homosexual and bisexual BIID patients (also 19 percent) (First, 2005; Lawrence, 2006). Comorbidity with depressive, anxiety or somatoform disorders have been described (First, 2005). But psychotherapy or pills do not generally change the minds of those afflicted with the disorder, although there is one report of a BIID patient feeling less miserable after taking anti-depressants and following cognitive behavioral therapy (Flor et al., 2002). Later this patient told that, although it was nice to talk to someone it did not change his desire for amputation at all.

A recent research on BIID and MRI have proved the tactile stimulation for undesired limb is reduced in its brain activity, involving the parietal lobe, suggesting the BIID might be cause by altered integration or somatosensory and propioceptive information (van Dijk et al., 2013). Curiously parital cortex has been related to body scheme for perception of the self in mytical experiences (Beauregard \& Paquette, 2006). There is evidence that the parietal cortex is part of the neuronal systeme implicated in the processing of visuospatial representation of the body schema in the process of self/other distintion (Neggers et al., 2006).

The BIID and the GD can be both explained by a mechanism hard-wiring where the body image is represented innately into the brain. It has been suggested the image of the sex organs of transsexuals are "hard-wired" in the brain in a manner which is opposite to that of their biological sex (Ramachandran \& McGeoch, 2007; Brang et al., 2008). This idea is based on the fact that in transsexual population a different pattern of phantom syndromes occurs after castration or breast extirpation (Ramachandram \& McGeogh, 2007; Brang et al., 2008). After gonadectomy and breast removal, transsexual patients experience a phantom syndrome less frequently than the non-transsexual population (Ramachandram \& McGeoch, 2007). Around $60 \%$ of men who have to have their pennies amputated for cancer will experience a phantom penis post-penectomy, but only $30 \%$ of the post-operative male-to-female transsexuals reported the incidence of a phantom penis. On the other hand surprisingly the $62 \%$ of the female-to-male transsexual patients reported having felt vivid phantom penises, including phantom erections for many years. Moreover only the $10 \%$ of those female to male transsexual patients experienced phantom breast sensations post-operatively (Ramachandram \& McGeoch, 2008).

One important difference between GD and BIID persons is the fact cortical reorganization might happen in different areas. For BIID the motor parietal area is crucial, while for genitals the location is more inside the brain, close to the foot representation in the Penfield homunculus (Ramachandram \& Hirstein, 1998). In some cases (19\%) these can be overlapped, but no so often, making them different diseases. Exclusion diagnosis have to be done for other identity disorders, such as the Body Integrity Identity Disorder (BIID), because the connection with transsexuality is especially intriguing in these cases due to the percentage of BIID subjects (19\%) (First, 2005; Lawrence, 2006) who also exhibit a gender dysphoric problem. In both cases the satisfying patient's demands for a surgical intervention still remains the only way to improve their clinical conditions and to avoid the onset of many other different and dramatic complications. Without any treatment the trouble might became chronic without remission and with high suicides rates.

\section{Psychology for Transsexualism}

Sexual minorities are at a higher risk of maltreatment and 
abuse (Corliss et al., 2002), together with their higher body dissatisfaction and a worse lifetime mental health reported. Maltreatment was defined in this study as an emotional abuse and/or neglect, physical abuse and/or neglect and sexual abuse (Bandini et al., 2011). However, an accurate mental health professional diagnosis is usually recommended to be made for the Gender Disorders (Hembree et al., 2009). Any treatment decisions, even when reversible, might always be taken by a whole clinical team after considering social and familiar circumstances (Kreukels \& Cohen-Kettenis, 2011). Since the benefits of clinical treatment for Gender Dysphoria are translated into a reduction of social ostracism, the complexities of sex-reassignment surgery, its biomedical treatment and the importance of reducing family psychopathologies or stress when they are present (Zucker et al., 2012) could be the clinical goals, together with an accurate and precise diagnosis, which are perspective to be always considered and supported. For those reasons a commitment of health in psychology/psychiatric and physicians/endocrine professionals to collaborate in understanding and properly care treating these difficult diseases (Hembree et al., 2009) would be required.

\section{Acknowledgements}

I thank Prof. Dick F. Swaab for his help in research and Dr. Jenneke Kruisbrink for her literature resource help.

\section{REFERENCES}

Allen, L. S., Hines, M., Shryne, J. E., \& Gorski, R. A. (1989). Two sexually dimorphic cell groups in the human brain. The Journal of Neuroscience, 9, 497-506.

http://www.jneurosci.org/content/9/2/497.long

Bandini, E., Fisher, A. D., Ricca, V., Ristori, J., Meriggiola, M. C., Jannini, E. A., Manieri, C., Corona, G., Monami, M., Fanni, E., Galleni, A., Forti, G., Mannucci, E., \& Maggi, M. (2011). Childhood maltreatment in subjects with male-to-female gender identity disorder. International Journal of Impotence Research, 23, 276-85.

http://dx.doi.org/10.1038/ijir.2011.39

Beauregard, M., \& Paquette, V. (2006). Neural correlates of a mystical experience in Carmelite nuns. Neuroscience Letters, 405, 186-190. http://dx.doi.org/10.1016/j.neulet.2006.06.060

Bentz, E. K., Hefler, L. A., Kaufmann, U., Huber, J. C., Kolbus, A., \& Tempfer, C. B. (2008). A polymorphism of the CYP17 gene related to sex steroid metabolism is associated with female-to-male but not male-to female transsexualism. Fertility and Sterility, 90, 56-59. http://dx.doi.org/10.1016/j.fertnstert.2007.05.056

Bentz, E. K., Schneeberger, C., Hefler, L. A., van Trotsenburg, M., Kaufmann, U., Huber, J. C., \& Tempfer, C. B. (2007). A common polymorphism of the SRD5A2 gene and transsexualism. Reproductive Sciences, 14, 705-709.

http://dx.doi.org/10.1177/1933719107306230

Blanchard, R. (1993). Partial versus complete autogynephilia and gender dysphoria. Journal of Sex \& Marital Therapy, 19, 301-307. http://dx.doi.org/10.1080/00926239308404373

Braam, A. W., Visser, S., Cath, D. C., \& Hoogendijk, W. J. (2006). Investigation of the syndrome of apotemnophilia and course of a cognitive-behavioural therapy. Psychopathology, 39, 32-37. http://dx.doi.org/10.1159/000089661

Brang, D., McGeoch, P. D., \& Ramachandran, V. S. (2008). Apotemnophilia: A neurological disorder. Neuroreport, 19, 1305-1306. http://dx.doi.org/10.1097/WNR.0b013e32830abc4d

Brugger, P., Lenggenhager, B., \& Giummarra, M. J. (2013). Xenomelia: A social neuroscience view of altered bodily self-consciousness. Frontiers in Psychology, 4, 204.

http://dx.doi.org/10.3389/fpsyg.2013.00204
Butler, J. (1975). "Of Personal Identity” in "The Analogy of Religion”. Berkeley: University of California Press.

Cohen-Kettenis, P. T., \& Gooren, L. J. (1999). Transsexualism: A review of etiology, diagnosis and treatment. Journal of Psychosomatic Research, 46, 315-333. http://dx.doi.org/10.1016/S0022-3999(98)00085-3

Corliss, H. L., Cochran, S. D., \& Mays, V. M. (2002). Reports of parental maltreatment during childhood in a United States populationbased survey of homosexual, bisexual and heterosexual adults. Child Abuse \& Neglect, 26, 1165-1178.

http://dx.doi.org/10.1016/S0145-2134(02)00385-X

DeFelipe, J., Conley, M., \& Jones, E. G. (1986). Long-range focal collateralization of axons arising from corticocortical cells in monkey sensory-motor cortex. The Journal of Neuroscience, 6, 3749-3766. http://www.jneurosci.org/content/6/12/3749.long

Eichenbaum, H., Schoenbaum, G., Young, B., \& Bunsey, M. (1996). Functional organization of the hippocampal memory system. Proceedings of the National Academy of Sciences of the United States of America, 93, 13500-13507. http://dx.doi.org/10.1073/pnas.93.24.13500

Fink, G. R., Markowitsch, H. J., Reinkemeier, M., Bruckbauer, T., Kessler, J., \& Heiss, W. D. (1996). Cerebral representation of one's own past: Neural networks involved in autobiographical memory. The Journal of Neuroscience, 16, 4275-4282. http://dx.doi.org/10.1093/brain/awg212

Fink, G. R. (2003). In search of one's own past: The neural bases of autobiographical memories. Brain, 126, 1509-1510. http://brain.oxfordjournals.org/content/126/7/1509.long

First, M. B., \& Fisher, C. E. (2012). Body integrity identity disorder: The persistent desire to acquire a physical disability. Psychopathology, 45, 3-14. http://dx.doi.org/10.1159/000330503

First, M. B. (2005). Desire for amputation of a limb: Paraphilia, psychosis, or a new type of identity disorder. Psychological Medicine, 35, 919-928.

http://dx.doi.org/10.1017/S0033291704003320

Flor, H. (2002). Phantom-limb pain: Characteristics, causes, and treatment. The Lancet Neurology, 3, 182-189. http://dx.doi.org/10.1016/S1474-4422(02)00074-1

Garcia-Falgueras, A., Ligtenberg, L., Kruijver, F. P., \& Swaab, D. F. (2011). Galanin neurons in the intermediate nucleus (InM) of the human hypothalamus in relation to sex, age, and gender identity. Journal of Comparative Neurology, 519, 3061-3084. http://dx.doi.org/10.1002/cne.22666

Garcia-Falgueras, A., \& Swaab, D. F. (2008). A sex difference in the hypothalamic uncinate nucleus: Relationship to gender identity. Brain, 131, 3132-3146. http://dx.doi.org/10.1093/brain/awn276

Hembree, W. C., Cohen-Kettenis, P., Delemarre-van de Waal, H. A., Gooren, L. J., Meyer 3rd, W. J., Spack, N. P., Tangpricha, V., \& Montori, V. M. (2009). Endocrine treatment of transsexual persons: An endocrine society clinical practice guideline. The Journal of Clinical Endocrinology \& Metabolism, 94, 3132-3154. http://dx.doi.org/10.1210/jc.2009-0345

Huh, J., Park, K., Hwang, I. S., Jung, S. I., Kim, H. J., Chung, T. W., \& Jeong, G. W. (2008). Brain activation areas of sexual arousal with olfactory stimulation in men: A preliminary study using functional MRI. The Journal of Sexual Medicine, 5, 619-625. http://dx.doi.org/10.1111/j.1743-6109.2007.00717.x

Khandelwal, A., Agarwal, A. \& Jiloha, R. C., (2010). A 47, XXY female with gender identity disorder. Archives of Sexual Behavior, 39, 1021-1023. http://link.springer.com/article/10.1007\%2Fs10508-010-9628-x

Kihlstrom, J. F., \& Klein, S. B. (1997). Self-knowledge and self-awareness. Annals of the New York Academy of Sciences, 818, 4-17. http://dx.doi.org/10.1111/j.1749-6632.1997.tb48242.x

Klempan, T., Hudon-Thibeault, A. A., Oufkir, T., Vaillancourt, C., \& Sanderson, J. T. (2011). Stimulation of serotonergic 5-HT2A receptor signaling increases placental aromatase (CYP19) activity and expression in BeWo and JEG-3 human choriocarcinoma cells. Placenta, 32, 651-656. http://dx.doi.org/10.1016/j.placenta.2011.06.003

Kreukels, B. P., \& Cohen-Kettenis, P. T. (2011). Puberty suppression in gender identity disorder: The Amsterdam experience. Nature Re- 


\section{A. GARCIA-FALGUERAS}

views Endocrinology, 7, 466-472.

http://dx.doi.org/10.1038/nrendo.2011.78

Lawrence, A. A. (2010). Sexual orientation versus age of onset as bases for typologies (subtypes) for gender identity disorder in adolescents and adults. Archives of Sexual Behavior, 39, 514-545. http://dx.doi.org/10.1007/s10508-009-9594-3

LeVay, S. (1991). A difference in hypothalamic structure between heterosexual and homosexual men. Science, 253, 1034-1037. http://dx.doi.org/10.1126/science.1887219

Locke, J. (1975). Of identity and diversity. In Essay concerning human understanding. Reprinted in John Perry John, 1975, Personal identity. Berkeley: University of California Press.

Looy, H., \& Bouma, H. (2005). The nature of gender: Gender identity in persons who are intersexed or transgendered. Journal of Psychology and Theology, 33, 166-178. http://journals.biola.edu/jpt/volumes/33/issues/3/articles/166

McGeoch, P. D., Brang, D., Song, T., Lee, R. R., Huang, M., \& Ramachandran, V. S. (2011). Xenomelia: A new right parietal lobe syndrome. Journal of Neurology, Neurosurgery \& Psychiatry, 82, 13141319. http://dx.doi.org/10.1136/jnnp-2011-300224

Money, J. (1977). Bisexual, homosexual, and heterosexual: Society, law, and medicine. Journal of Homosexuality, 2, 229-233. http://dx.doi.org/10.1300/J082v02n03_05

Neggers, S. F., Van der Lubbe, R. H., Ramsey, N. F., \& Postma, A. (2006). Interactions between ego- and allocentric neuronal representations of space. Neuroimage, 31, 320-331. http://dx.doi.org/10.1016/j.neuroimage.2005.12.028

Ngun, T. C., Ghahramani, N., Sánchez, F. J., Bocklandt, S., \& Vilain, E. (2011). The genetics of sex differences in brain and behavior. Frontiers in Neuroendocrinology, 32, 227-246. http://dx.doi.org/10.1016/j.yfrne.2010.10.001

Nimbalkar, N. (2011). John locke on personal identity. Mens Sana Monogr, 9, 268-275.

Nishizawa, S., Benkelfat, C., Young, S. N., Leyton, M., Mzengeza, S., de Montigny, C., Blier, P., \& Diksic, M. (1997). Differences between males and females in rates of serotonin synthesis in human brain. Proceedings of the National Academy of Sciences of the United States of America, 94, 5308-5313. http://www.pnas.org/content/94/10/5308.long

Ott, C. (2004). The evolution of perception and the cosmology of substance, James W: Principles of psychology, volume 1. New York: Henry-Holt \& Co.

Phillips, K. A., Wilhelm, S., Koran, L. M., Didie, E. R., Fallon, B. A., Feusner, J., \& Stein, D. J. (2010). Body dysmorphic disorder: Some key issues for DSM-V. Depress Anxiety, 27, 573-591. http://onlinelibrary.wiley.com/doi/10.1002/da.20709/abstract

Ramachandran, V. S., \& McGeoch, P. D. (2008). Phantom penises in transsexuals evidence of an innate gender-specific body image in the brain. Journal of Consciousness Studies, 15, 5-16. http://www.imprint.co.uk/jcs 15 1.html\#rama

Ramachandran, V. S., \& Hirstein, W. (1998). The perception of phantom limbs. The D. O. Hebb lecture. Brain, 121, 1603-1630. http://dx.doi.org/10.1093/brain/121.9.1603

Ramachandran, V. S., \& McGeoch, P. D. (2007). Occurrence of phantom genitalia after gender reassignment surgery. Medical Hypotheses, 69, 1001-1003. http://dx.doi.org/10.1016/j.mehy.2007.02.024

Rauch, S. L., Shin, L. M., Dougherty, D. D., Alpert, N. M., Orr, S. P., Lasko, M., Macklin, M. L., Fischman, A. J., \& Pitman, R K. (1999). Neural activation during sexual and competitive arousal in healthy men. Psychiatry Research, 91, 1-10. http://dx.doi.org/10.1016/S0925-4927(99)00020-7

Ruhe, H. G., Mason, N. S., \& Schene, A. H. (2007). Mood is indirectly related to serotonin, norepinephrine and dopamine levels in humans: A meta-analysis of monoamine depletion studies. Molecular Psychiatry, 12, 331-359. http://dx.doi.org/10.1038/sj.mp.4001949

Smith, Y. L., van Goozen, S. H., Kuiper, A. J., \& Cohen-Kettenis, P. T. (2005). Transsexual subtypes: Clinical and theoretical significance. Psychiatry Research, 137, 151-160. http://dx.doi.org/10.1016/j.psychres.2005.01.008

Sollberger, D. (2013). On identity: From a philosophical point of view. Child and Adolescent Psychiatry and Mental Health, 7, 29. http://dx.doi.org/10.1186/1753-2000-7-29

Stafford, N. (2013). Germany is first European country to recognise third sex on birth certificates. BMJ, 22, Article ID: f5249. http://dx.doi.org/10.1136/bmj.f5249

van Dijk, M. T., van Wingen, G. A., van Lammeren, A., Blom, R. M., de Kwaasteniet, B. P., Scholte, H. S., \& Denys, D. (2013). Neural basis of limb ownership in individuals with body integrity identity disorder. PLoS One, 8, Article ID: e72212. http://dx.doi.org/10.1371/journal.pone.0072212

Viard, A., Piolino, P., Desgranges, B., Chételat, G., Lebreton, K., Landeau, B., Young, A., De La Sayette, V., \& Eustache, F. (2007). Hippocampal activation for autobiographical memories over the entire lifetime in healthy aged subjects: An fMRI study. Cereb Cortex, 17, 2453-2467. http://dx.doi.org/10.1093/cercor/bhl153

Zucker, K. J., Wood, H., Singh, D., \& Bradley, S. J. (2012). A developmental, biopsychosocial model for the treatment of children with gender identity disorder. Journal of Homosexuality, 59, 369-397. http://dx.doi.org/10.1080/00918369.2012.653309 